\title{
PECAM-1 GENE POLYMORPHISM (rs668) AND SUBCLINICAL MARKERS OF CAROTID ATHEROSCLEROSIS IN PATIENTS WITH TYPE 2 DIABETES MELLITUS
}

\author{
Popović D ${ }^{1}$, Nikolajević Starčević J², Šantl Letonja $\mathrm{M}^{1}$, Makuc J33, \\ Cokan Vujkovac A3 ${ }^{3}$, Reschner $\mathrm{H}^{4}$, Bregar D $\mathrm{D}^{1}$, Petrovič $\mathrm{D}^{2,5}$
}

*Corresponding Author: Professor Daniel Petrovič, M.D., Ph.D., Institute of Histology and Embryology, Faculty of Medicine University Ljubljana, Korytkova 2, SI-1000 Ljubljana, Slovenia. Tel: +386-1-543-7367. Fax:+386-1-543-7361. E-mail: daniel.petrovic@mf.uni-lj.si

\begin{abstract}
The platelet endothelial cell adhesion molecule 1 (PECAM-1) plays an important role in many inflammatory processes, including the development of atherosclerosis. Polymorphism rs668 of the PECAM-1 gene $(373 \mathrm{C} / \mathrm{G})$ is functional, and it was reported to be associated with increased serum levels of PECAM-1. We investigated the association between the rs668 polymorphism of PECAM-1 and subclinical markers of carotid atherosclerosis in subjects with type 2 diabetes mellitus (T2DM). Five hundred and ninetyfive T2DM subjects and 200 control subjects were enrolled. The carotid intima-media thickness (CIMT) and plaque characteristics (presence and structure) were assessed ultrasonographically. Biochemical analyses were performed using standard biochemical methods. Geno-typing of the PECAM-1 gene polymorphism (rs668) was performed using KASPar assays. The control examinations were performed $3.8 \pm$ 0.5 years after the initial examination. Higher CIMT was found in patients with T2DM in comparison with subjects without T2DM. Statistically sig-nificantly faster progression of the atherosclerotic markers was
\end{abstract}

\footnotetext{
${ }^{1}$ General Hospital Rakičan, Murska Sobota, Slovenia

${ }^{2}$ Institute of Histology and Embryology, Faculty of Medicine, University in Ljubljana, Ljubljana, Slovenia

${ }^{3}$ General Hospital Slovenj Gradec, Slovenj Gradec, Slovenia

${ }^{4}$ Zdravstveni Zavod Reschner, Ljubljana, Slovenia

${ }^{5}$ Cardiology Outpatient Department Medical Center Medicor, Ljubljana, Slovenia
}

shown in subjects with T2DM in comparison with the control group. When adjusted to other risk factors, the rs668 GG genotype was associated with an increased risk of carotid plaques in subjects with T2DM. We concluded that our study demonstrated a minor effect of the rs668 PECAM-1 on markers of carotid atherosclerosis in subjects with T2DM.

Keywords: Association study; carotid atherosclerosis; Platelet endothelial cell adhesion molecule 1 (PECAM-1); rs668 polymorphism; type 2 diabetes mellitus (T2DM).

\section{INTRODUCTION}

The leukocyte adhesion and their transendothelial migration play an important role in the initial phase of atherogenesis [1]. Processes are regulated by various types of adhesion molecules, such as platelet endothelial cell adhesion molecule 1 (PECAM-1), intercellular adhesion molecule 1 (ICAM-1) and vascular cell adhesion molecule 1 (VCAM-1). The plasma level of adhesion molecules is elevated in individuals with atherosclerosis [2-4].

Platelet endothelial cell adhesion molecule 1, also called CD31, is a $130 \mathrm{kD}$ member of the immunoglobulin superfamily, consisting of six extracellular immunoglo-bulin-like domains, one transmembrane domain, and one cytoplasmic domain. Their expression takes place on the surface of circulating platelets, monocytes, neutrophils and selected T cells $[5,6]$. The PECAM-1 is a signaling molecule that plays diverse roles in vascular biology, including 
modulation of platelet function [7,8], angiogenesis [9], vasculogenesis [10], integrin regulation [11], T-cell and B-cell activation [12] and mediation of leukocyte migration across the endothelium [13].

The PECAM-1 gene is located at the end of the long arm of the chromosome 17 (17q23). Previous studies have reported the existence of 11 different single nucleotide polymorphisms (SNPs) of the PECAM-1 gene. Three of them have been described that encode amino acid substitutions in the PECAM-1 molecule. A mutation in the PECAM-1 gene in exon 3 at position +373 involves a $C>G$ substitution, causing a leucine to valine substitution at position 125 (rs668) [14].

The interaction or activation of the PECAM- 1 take place via homophilic binding with its first extracellular Ig-like domains $[15,16]$. This polymorphism might affect the homophilic binding capability and influence individual susceptibility to the development of atherosclerosis. The association between the rs668 PECAM-1 polymorphism and cardiovascular disease was studied in Caucasians [17-19], Japanese [20] and Chinese [21], but no clear answer on the association between the rs668 polymorphism of PECAM-1 and the development of cardiovascular diseases could be provided.

Platelet endothelial cell adhesion molecule 1 is important in the detection of mechanoreception (mechanical shear force) and mechanotransduction (conversion into chemical signals) by the endothelium $[22,23]$. Atherosclerotic lesion development occurs at sites of the vessel where flow and shear stress conditions are disturbed [24]. Pulsatile or oscillatory shear stresses induce pro inflammatory gene expression [25]. Using the mouse model, the effect of PECAM-1 deficiency (double knock-out mice model without the presence of the PECAM-1 gene) on the development of atherosclerosis. They reported reduced atherosclerotic lesions in double knock-out mice models $[21,25]$. The purpose of this study was to investigate an association between the rs668 $(+373 \mathrm{C} / \mathrm{G})$ polymorphism of the PECAM-1 gene and subclinical markers of carotid atherosclerosis in patients with type 2 diabetes mellitus (T2DM).

\section{PATIENTS AND METHODS}

This study included 595 consecutive subjects with T2DM, admitted to the diabetes outpatient clinics of the general hospitals at Murska Sobota and Slovenj Gradec, Slovenia, and from the outpatient department at the Medical Center Medicor, Ljubljana, Slovenia. The inclusion criteria for the control group was the absence of T2DM, and consisted of employees of the General Hospital Murska Sobota, Slovenia. Another inclusion criteria for the subjects with T2DM and for the subjects in the control group was the age from 40 to 70 . The exclusion criteria for subjects with T2DM and for the subjects in the control group was a history of either myocardial infarction (MI) or ischemic stroke. The study protocol was approved by the Slovene Medical Ethics Committee (98/08/10). The patients and control subjects were enrolled and followed in the period from 2008 to 2014 .

Patients were classified as having T2DM according to the current report of the American Diabetes Association [26]. After informed consent was obtained from the patients, a detailed interview was conducted concerning smoking habits, the duration and treatment of diabetes, arterial hypertension, and hyperlipidemia. Patients were asked whether they were smokers at the time of recruitment (current smoker). Subjects with T2DM with systolic blood pressure $\geq 140.0 \mathrm{~mm} \mathrm{Hg}$ or diastolic blood pressure $\geq 85.0 \mathrm{~mm}$ $\mathrm{Hg}$ and/or subjects who were taking anti hypertensive drugs were considered to be hypertensive.

All ultrasound examinations were performed by two experienced doctors blinded to the participants' diabetes status. The carotid intima-media thickness (CIMT), defined as the distance from the leading edge of the lumen-intima interface to the leading edge of the media-adventitia interface, was measured as previously described [27]. Plaques were defined as a focal intima-media thickening, and divided into five types according to their echogenic/ echolucent characteristics, as previously described [27]. The interobserver reliability for carotid plaque characterization was found to be substantial $(\kappa=0.64, p<0.001)$.

After the patients with T2DM and subjects without T2DM (control group) were enrolled, they were prospectively followed-up for a few years. From the group with T2DM, 426 responded and participated in the control ultrasound examination of the neck artery, whereas, 132 re-sponded from the group of subjects without T2DM; $3.8 \pm 0.5$ years passed between the first and the control ultrasound examination.

Biochemical Analyses. Fasting blood samples for biochemical analysis were collected twice patients: upon enrollment and upon follow-up after a few years. Analyses were made at the hospital ac- 
credited laboratory. The following parameters were determined: total cholesterol, triglycerides, highdensity lipoprotein (HDL), low-density lipoprotein (LDL), blood sugar and high-sensitive C-reactive protein (hsCRP).

Genotyping. Genomic DNA was extracted from $100 \mu \mathrm{L}$ of whole blood using a FlexiGene DNA isolation kit (Qiagen GmbH, Hilden, Germany), in accordance with the recommended protocol. The rs668 polymorphism of the PECAM-1 gene was determined with the KASPar assay (LGC Genomics Ltd., Hoddesdon, Hertfordshire, UK) system.

Statistical Analyses. Continuous variables that were normally distributed, were reported in the form of mean \pm standard deviation (SD). Variables that were not normally distributed, were presented in the form of median (inter-quartile range). The normality of distribution of continuous variables was examined using the Kolmogorov-Smirnov test. We used the Student's $t$ test or the analysis of variance (ANOVA) to compare the numerical values of the continuous variables, to identify the distribution of variables. If the variables were asymmetrically distributed, we used the Mann-Whitney U test or the Kruskal-Wallis $\mathrm{H}$ test. The $\chi^{2}$ test was used to compare the frequency's categorical variables, statistical evaluation of differences in the frequencies of different alleles and genotypes between the two groups, as well as in the case of determining the Hardy-Weinberg equilibrium.

The Pearson analyses was performed to examine the correlation between the independent variables. The results showed a high degree of correlation between the serum levels of total and LDL cholesterol $(r=0.86 ; p<0.001)$, as well as systolic and diastolic blood pressure $(r=0.65 ; p<0.001)$. In the case of a high degree correlation between two variables, only one variable from each pair was included in the multivariate statistical models.

The change in the value of ultrasound markers of carotid artery atherosclerosis was calculated by deducting the values measured at two ultrasound examinations. The criteria for a statistically significant difference was a $p$ value of less than 0.05 . To reduce the possibility of error due to the small number of subjects, we used the Bonferroni correction. All statistical analyses were performed using the Statistical Package for the Social Sciences (SPSS) computer program for Windows, version 20 (SPSS Inc., Chicago, IL, USA).

\section{RESULTS}

The clinical characteristics of subjects with T2DM and control subjects are shown in Table 1. Patients with T2DM had a greater waist circumference and there

Table 1. Initial clinical and biochemical characteristics of patients with type 2 diabetes mellitus and the control group.

\begin{tabular}{|c|c|c|c|}
\hline Parameters & Patients with T2DM $(n=529)$ & Control Group $(n=200)$ & $p$ Value \\
\hline Age $($ mean $\pm \mathrm{SD})$ & $61.38 \pm 9.65$ & $60.07 \pm 9.18$ & 0.07 \\
\hline Sex: M (\%); F (\%) & M: 338 (56.8); F: 191 (43.2) & M: 92 (46.0); F: 108 (54.0) & 0.008 \\
\hline Duration of T2DM & $11.5 \pm 7.88$ & - & - \\
\hline Smokers: M (\%); F (\%) & M: 30 (8.9); F: 23 (12.0) & M: 19 (20.6); F: 15 (13.9) & 0.002 \\
\hline Waist circumference $(\mathrm{cm})$ & $108.65 \pm 12.88$ & $93.31 \pm 13.18$ & $<0.001$ \\
\hline BMI $\left(\mathrm{kg} / \mathrm{m}^{2}\right)$ & $30.96 \pm 4.74$ & $27.90 \pm 4.42$ & 0.16 \\
\hline Systolic pressure (mm Hg) & $146.98 \pm 19.98$ & $143.30 \pm 16.60$ & 0.86 \\
\hline Diastolic pressure $(\mathrm{mm} \mathrm{Hg})$ & $85.75 \pm 11.62$ & $84.70 \pm 11.60$ & 0.19 \\
\hline Fasting glucose (mmol/L) & $8.04 \pm 2.57$ & $5.27 \pm 0.87$ & $<0.001$ \\
\hline $\mathrm{Hb} \mathrm{A}_{1 \mathrm{c}}(\%)$ & $7.89 \pm 3.56$ & $4.79 \pm 0.29$ & $<0.001$ \\
\hline Total cholesterol $(\mathrm{nmol} / \mathrm{L})$ & $4.70 \pm 1.19$ & $5.36 \pm 1.08$ & $<0.001$ \\
\hline HDL cholesterol (mmol/L) & $1.19 \pm 0.35$ & $1.43 \pm 0.37$ & $<0.001$ \\
\hline LDL cholesterol $(\mathrm{mmol} / \mathrm{L})$ & $2.63 \pm 0.94$ & $3.24 \pm 0.98$ & $<0.001$ \\
\hline Triglycerides $(\mathrm{mmol} / \mathrm{L})$ & $1.90(1.20-2.70)$ & $1.30(0.90-1.90)$ & $<0.001$ \\
\hline High sensitivity CRP (mg/L) & $2.20(1.00-4.30)$ & $1.30(0.80-2.70)$ & $<0.001$ \\
\hline CIMT $(\mu \mathrm{m})$ & $1013.00 \pm 208.00$ & $979.00 \pm 141.00$ & 0.030 \\
\hline
\end{tabular}

T2DM: type 2 diabetes mellitus; BMI: body mass index; HDL: high-density lipoprotein; LDL: low-density lipoprotein; CRP: C-reactive protein; CIMT: carotid intima-media thickness. 
Table 2. Changes in ultrasound markers of atherosclerosis at carotid artery in patients with type 2 diabetes mellitus and the control group between the initial and control ultrasound examinations.

\begin{tabular}{|l|c|c|c|}
\hline Parameters & Patients with T2DM $(\boldsymbol{n}=\mathbf{4 2 6})$ & Control Group $(\boldsymbol{n}=\mathbf{1 3 7})$ & $\mathbf{0 . 5 0}$ \\
\hline Annual CIMT increment $(\mu \mathrm{m} / \mathrm{year})$ & $20.33(11.74-29.86)$ & $12.83(8.82-20.66)$ & $\mathbf{0 . 0 0}$ \\
\hline$\Delta$ number of plaque segments & $2.00(1.00-3.00)$ & $1.50(0.70-2.20)$ & $\mathbf{0 . 0 0}$ \\
\hline$\Delta$ sum of the plaque thickness $(\mathrm{mm})$ & $5.40(2.40-7.05)$ & $3.64(2.88-5.48)$ & $\mathbf{0 . 0 2}$ \\
\hline
\end{tabular}

CIMT: carotid intima-media thickness; $\Delta$ : variable value changes during the observation period, expressed as a percentage of baseline values.

Table 3. Comparison of ultrasound markers of the carotid artery atherosclerosis in patients with type 2 diabetes mellitus according to the PECAM gene polymorphism $373 \mathrm{C} / \mathrm{G}$ (rs668) genotypes at the beginning of the study.

\begin{tabular}{|l|c|c|c|c|}
\hline Parameters & CC Genotype & CG Genotype & GG Genotype & $\boldsymbol{p}$ value \\
\hline CIMT $(\mu \mathrm{m})$ & $1041.00 \pm 198.00$ & $990.00 \pm 187.00$ & $988.00 \pm 211.00$ & 0.19 \\
\hline Number of segments with plaques & $2.56 \pm 1.65$ & $2.39 \pm 1.72$ & $2.51 \pm 1.54$ & 0.36 \\
\hline Sum of the plaque thickness $(\mathrm{mm})$ & $8.14 \pm 4.77$ & $7.99 \pm 5.23$ & $7.66 \pm 4.02$ & 0.16 \\
\hline Presence of plaques: $[+]$ & $149.00(85.60)$ & $256.00(84.50)$ & $94.00(79.70)$ & 0.36 \\
{$[-]$} & $25.00(14.40)$ & $47.00(15.50)$ & $24.00(20.30)$ & \\
\hline Presence of unstable plaques: $[+]$ & $86.00(57.70)$ & $144.00(56.30)$ & $58.00(61.70)$ & 0.66 \\
\hline-$]$ & $63.00(42.30)$ & $112.00(43.70)$ & $36.00(38.30)$ & \\
\hline
\end{tabular}

CIMT: carotid intima-media thickness.

Table 4. Changes in ultrasound markers of carotid artery atherosclerosis in patients with type 2 diabetes mellitus between the first and the second ultrasound examination of the carotid arteries according to the PECAM gene polymorphism $373 \mathrm{C} / \mathrm{G}(\mathrm{rs} 668)$ genotypes.

\begin{tabular}{|l|c|c|c|c|}
\hline Parameters & CC Genotype & CG Genotype & GG Genotype & $\boldsymbol{p}$ Value \\
\hline Annual CIMT increment $(\mu \mathrm{m} / \mathrm{year})$ & $20.34(11.64-28.04)$ & $20.69(7.14-32.28)$ & $14.28(10.71-35.97)$ & 0.71 \\
\hline$\Delta$ number of plaque segments & $2.00(0.50-2.50)$ & $2.00(1.00-3.00)$ & $2.00(2.00-3.00)$ & 0.74 \\
\hline$\Delta$ sum of the plaque thickness $(\mathrm{mm})$ & $7.30(3.85-8.70)$ & $5.45(2.30-9.20)$ & $4.40(1.40-8.42)$ & 0.38 \\
\hline
\end{tabular}

CIMT: carotid intima-media thickness; $\Delta$ : variable value changes during the observation period, expressed as a percentage of baseline values.

were more smokers compared to the control group. There were no statistically significant differences between patients with T2DM and controls in other clinical characteristics [age, body mass index (BMI), systolic and diastolic pressure]. A biochemical examination of patients with T2DM showed statistically significant higher levels of fasting glucose, $\mathrm{Hb} \mathrm{A}_{1 \mathrm{c}}$, total cholesterol, HDL, LDL, triglyceride and hsCRP compared with the control group (Table 1). Moreover, higher CIMT was found in patients with T2DM in comparison with subjects without T2DM (Table 1).

The ultrasound examination of the carotid artery was performed at the time of enrollment in the study, and $3.8 \pm 0.5$ years after the initial examination. Changes in the progression of atherosclerotic markers (change in annual CIMT increase, change in the number of plaque segments and change in the sum of the plaque thickness) between subjects with T2DM and the control group are shown in Table 2. Statistically significantly faster progression of the atherosclerotic markers was shown in subjects with T2DM in comparison with the control group (Table 2).

The distribution of genotypes in the population of patients with T2DM was in Hardy-Weinberg equilibrium (T2DM: $\chi^{2}=0.45 ; p=0.50$; control group: $\chi^{2}=1.46 ; p=0.23$ ). Table 3 outlines differences in the ultrasound markers of carotid artery atherosclerosis (initial ultrasound examination) in patients with T2DM with regard to the rs668 genotypes. The differences were not statistically significant with regard to rs668 genotypes (Table 3). We did not demonstrate statistically significant differences in the markers of subclinical carotid atherosclerosis between different genotypes in subjects with T2DM (Table 4).

Table 5 shows the relation between the rs 668 and the incidence of either plaques or unstable plaques 
Table 5. Relationship of the PECAM gene polymorphism $373 \mathrm{C} / \mathrm{G}$ (rs668) genotypes to the presence of plaques/ unstable plaques of the carotid arteries in patients with type 2 diabetes mellitus at the beginning of the study.

\begin{tabular}{|l|c|c|c|c|}
\hline & \multicolumn{2}{|c|}{ Presence of Plaques } & \multicolumn{2}{c|}{ Presence of Unstable Plaques } \\
\hline Parameters & OR $(\mathbf{9 5 \%}$ CI) & $\boldsymbol{p}$ Value & OR (95\% CI) & $\boldsymbol{p}$ Value \\
\hline Hypertension $(0=\mathrm{no} ; 1=$ yes) & 1.88 & 0.35 & 1.38 & 0.52 \\
\hline Systolic pressure (mm Hg) & 0.24 & 0.68 & 0.26 & 0.32 \\
\hline Serum LDL (mmol/L) & 1.41 & 0.41 & 1.34 & 0.25 \\
\hline Serum HDL (mmol/L) & 0.11 & $\mathbf{0 . 0 2}$ & 0.31 & 0.34 \\
\hline Hb A 1 (\%) & 0.89 & $\mathbf{0 . 0 3}$ & 1.23 & 0.43 \\
\hline CG allele & 1.03 & 0.49 & 0.72 & 0.17 \\
\hline GG allele & 1.18 & $\mathbf{0 . 0 3}$ & 0.68 & 0.51 \\
\hline
\end{tabular}

OR (95\% CI): odds ratio (95\% confidence interval); LDL: low-density lipoprotein; HDL: high-density lipoprotien; all models were adjusted by age, sex, smoking habits and treatment with statins. The reference group are homozygotes for the $\mathrm{C}$ allele (the CC genotype).

in subjects with T2DM. When adjusted to other risk factors, the rs668 GG genotype was associated with an increased risk of carotid plaques in subjects with T2DM (Table 5).

\section{DISCUSSION}

In the present study, we demonstrated an association between the rs668 GG genotype and carotid artery plaque incidence in patients with T2DM when adjusted to other risk factors. On the other hand, we did not find any effect of the rs688 genotype on the progression of atherosclerosis in patients with T2DM.

Our study is the first demonstrating an association between the rs668 PECAM- 1 and the presence of carotid plaques in patients with T2DM. In our study, we observed a greater number of plaques in subjects with the GG rs668 genotype. The importance of the PECAM-1 gene in the pathogenesis of atherosclerosis was demonstrated $[21,25]$. The decrease in areas with atherosclerotic lesion in PECAM-1 double knock-out mice was reported $[21,25]$.

An association between the rs668 PECAM-1 and car-diovascular disorders was reported several times, but not in all studies [29-33]. Similarly, an association between the rs668 PECAM-1 gene and either the increased levels of soluble PECAM-1 or ischemic stroke was found in the Chinese population [21]. An association between the rs668 PECAM-1 gene and increased levels of soluble PECAM-1 was confirmed in the setting of patients with acute MI [28].

Similarly, Fang et al. [29] demonstrated an association between the rs668 PECAM-1 gene and either increased levels of soluble PECAM-1 or the severity of coronary artery disease in the Asian Indian population in Singapore. Reschner et al. [17] reported an association between the PECAM-1 rs668 (the CC genotype) and MI in Caucasians with T2DM. Finally, the effect of several polymorphisms of the PECAM-1 gene on cardiovascular disease was confirmed by Listi et al. [30] in the Northern Italian population. These findings were not confirmed in the general population from Germany, as rs688 was not found to be an independent risk factor for coronary artery disease (CAD) [31].

In a recently published meta-analysis of 15 studies, including 7636 subjects, no association between the rs668 PECAM-1 and cardiovascular diseases was demonstrated [35]. Moreover, the progression of subclinical markers of carotid atherosclerosis was statistically significantly faster in subjects with T2DM in comparison with subjects without T2DM. This finding is in accordance with expectations of other researchers as well $[32,33]$.

Our study has some limitations due to its actual design (cross-sectional design at the enrollment of subjects with T2DM and control subjects) and relatively small sample size (i.e., less than 1000 subjects with T2DM), however the study was appropriately powered to detect the differences in subclinical markers of carotid atherosclerosis upon enrollment as well as during follow-up. The lack of the effect of rs688 on the progression of atherosclerosis might be due to a rather short interval between the first and control examinations ( $3.8 \pm 0.5$ years). Moreover, it is impossible to exclude the impact of interactions with other 
potentially relevant variables on the development of atherosclerosis. The second limitation of the study is the lack of an intermediate phenotype, i.e., serum PECAM levels. We presume that the effect of rs668 is via increased serum PECAM levels.

In conclusion, our study demonstrated a minor effect of the rs668 PECAM-1 on the markers of carotid atherosclerosis in subjects with T2DM, as the GG genotype of the rs668 PECAM-1 was associated with a higher incidence of carotid plaques in subjects with T2DM. With that kind of associations established in genetic studies, we presumed that we might predict the genetic risk of carotid atherosclerosis in subjects with T2DM.

\section{ACKNOWLEDGMENTS}

The authors thank Mrs. Brina Beskonik, B.A., Jeziček Brina Beškovnik s.p., Portoroz-Portorose, Slovenia, for revising the English.

Declaration of Interest. The authors report no conflicts of interest. The authors alone are responsible for the content and writing of this article.

\section{REFERENCES}

1. Cybulsky MI, Gimbrone MA. Endothelial expression of a mononuclear leukocyte adhesion molecule during atherogenesis. Science. 1991; 251(4995): 788-791.

2. Peter $\mathrm{K}$, Nawroth $\mathrm{P}$, Conradt $\mathrm{C}$, Nordt $\mathrm{T}$, Weiss $\mathrm{T}$, Boehme $\mathrm{M}$, et al. Circulating vascular cell adhesion molecule-1 correlates with the extent of human atherosclerosis in contrast to circulating intercellular adhesion molecule-1, E-selectin, P-selectin, and thrombomodulin. Arterioscler Thromb Vasc Biol. 1997; 17(3): 505-512.

3. Hwang S-J, Ballantyne CM, Sharrett AR, Smith LC, Davis CE, Gotto AM Jr, et al. Circulating adhesion molecules VCAM-1, ICAM-1, and Eselectin in carotid atherosclerosis and incident coronary heart disease cases. The Atherosclerosis Risk In Communities (ARIC) Study. Circulation. 1997; 96(12): 4219-4225.

4. Rohde LE, Lee RT, Rivero J, Jamacochian M, Arroyo LH, Briggs W, et al. Circulating cell adhesion molecules are correlated with ultrasoundbased assessment of carotid atherosclerosis.
Arterioscler Thromb Vasc Biol. 1998; 18(11): 1765-1770.

5. Albelda SM, Oliver PD, Romer LH, Buck CA. EndoCAM: A novel endothelial cell-cell adhesion molecule. J Cell Biol. 1990; 110(4): 12271237.

6. Newman PJ, Berndt MC, Gorski J, White GC 2nd, Lyman S, Paddock C, et al. PECAM-1 (CD31) cloning and relation to adhesion molecules of the immunoglobulin gene superfamily. Science. 1990; 247(4947): 1219-1222.

7. Cicmil M, Thomas JM, Sage T, Barry FA, Leduc $\mathrm{M}$, Bon C, et al. Collagen, convulxin, and thrombin stimulate aggregation-independent tyrosine phosphorylation of CD31 in platelets. Evidence for the involvement of Src family kinases. J Biol Chem. 2000; 275(35): 27339-27347.

8. Falati S, Patil S, Gross PL, Stapleton M, MerrillSkoloff G, Barrett NE, et al. Platelet PECAM-1 inhibits thrombus formation in vivo. Blood. 2006; 107(2): 535-541.

9. Matsumura T, Wolff K, Petzelbauer P. Endothelial cell tube formation depends on cadherin 5 and CD31 interactions with filamentous actin. J Immunol. 1997; 158(7): 3408-3416.

10. Breier G, Breviario F, Caveda L, Berthier R, Schnüch $\mathrm{H}$, Gotsch U, et al. Molecular cloning and expression of murine vascular endothelialcadherin in early stage development of cardiovascular system. Blood. 1996; 87(2): 630-641.

11. Piali L, Albelda SM, Baldwin HS, Hammel P, Gisler RH, Imhof BA. Murine platelet endothelial cell adhesion molecule (PECAM-1)/CD31 modulates beta 2 integrins on lymphokine-activated killer cells. Eur J Immunol. 1993; 23(10): 2464-2471.

12. Newton-Nash DK, Newman PJ. A new role for platelet-endothelial cell adhesion molecule-1 (CD31): inhibition of TCR-mediated signal transduction. J Immu-nol. 1999; 163(2): 682-688.

13. Duncan GS, Andrew DP, Takimoto H, Kaufman $\mathrm{SA}$, Yoshida H, Spellberg J, et al. Genetic evidence for functional redundancy of platelet/endothelial cell adhesion molecule-1 (PECAM-1): CD31-deficient mice reveal PECAM-1-dependent and PECAM-1-independent func-tions. $\mathrm{J}$ Immunol. 1999; 162(5): 3022-3030. 
14. Behar E, Chao NJ, Hiraki DD, Krishnaswamy $\mathrm{S}$, Brown BW, Zehnder JL, et al. Polymorphism of adhesion molecule CD31 and its role in acute graft-versus-host disease. N Engl J Med. 1996; 334(5): 286-291.

15. Muller WA, Weigl SA, Deng X, Phillips DM. PECAM-1 is required for transendothelial migration of leukocytes. J Exp Med. 1993; 178(2): 449-460.

16. Sun J, Williams J, Yan HC, Amin KM, Albelda SM, DeLisser HM. Platelet endothelial cell adhesion molecule-1 (PECAM-1) homophilic adhesion is mediated by immunoglobulin-like domains 1 and 2 and depends on the cytoplasmic domain and the level of surface expression. $\mathrm{J}$ Biol Chem. 1996; 271(31): 18561-18570.

17. Reschner H, Milutinovič A, Petrovič D. The PECAM-1 gene polymorphism - A genetic marker of myocardial infarction. Cent Eur J Biol. 2009; 4(4): 515-520.

18. Wenzel K, Baumann G, Felix SB. The homozygous combination of Leu125Val and Ser563Asn polymorphisms in the PECAM1 (CD31) gene is associated with early severe coronary heart disease. Hum Mutat. 1999; 14(6): 545.

19. Gardemann A, Knapp A, Katz N, Tillmanns H, Haberbosch W. No evidence for the CD31 C/G gene polymorphism as an independent risk factor of coronary heart disease. Thromb Haemost. 2000; 83(4): 629.

20. Sasaoka T, Kimura A, Hohta SA, Fukuda N, Kurosawa T, Izumi T. Polymorphisms in the platelet-endothelial cell adhesion molecule-1 (PECAM-1) gene, Asn563 Ser and Gly670Arg, associated with myocardial infarction in the Japanese. Ann NY Acad Sci. 2001; 947: 259269; discussion 269-270.

21. Wei H, Fang L, Chowdhury SH, Gong N, Xiong $\mathrm{Z}$, Song J, et al. Platelet-endothelial cell adhesion molecule-1 gene polymorphism and its soluble level are associated with severe coronary artery stenosis in Chinese Singaporean. Clin Biochem. 2004; 37(12): 1091-1097.

22. Fleming I, Fisslthaler B, Dixit M, Busse R. Role of PECAM-1 in the shear-stress-induced activation of Akt and the endothelial nitric oxide synthase (eNOS) in endothelial cells. J Cell Sci. 2005; 118(Pt 18): 4103-4111.
23. Bagi Z, Frangos JA, Yeh JC, White CR, Kaley G, Koller A. PECAM-1 mediates NO-dependent dilation of arterioles to high temporal gradients of shear stress. Arterioscler Thromb Vasc Biol. 2005; 25(8): 1590-1595.

24. DeBakey ME, Lawrie GM, Glaeser DH. Patterns of atherosclerosis and their surgical significance. Ann Surg. 1985; 201(2): 115-131.

25. Bao X, Lu C, Frangos JA. Temporal gradient in shear but not steady shear stress induces PDGFA and MCP-1 expression in endothelial cells: role of NO, NF kappa B, and egr-1. Arterioscler Thromb Vasc Biol. 1999; 19(4): 996-1003.

26. American Diabetes Association. Diagnosis and Classification of Diabetes Mellitus. Diabetes Care. 2012; 35(Suppl 1): S64-S71 (http://dx.doi. org/10.2337/dc12-s064).

27. Serebruany VL, Murugesan SR, Pothula A, Atar $\mathrm{D}$, Lowry DR, O'Connor CM, et al. Increased soluble platelet/endothelial cellular adhesion molecule-1 and osteonectin levels in patients with severe congestive heart failure. Independence of disease etiology, and antecedent aspirin therapy. Eur J Heart Fail. 1999; 1(3): 243-249.

28. Shalia KK, Mashru MR, Soneji SL, Shah VK, Payannavar S, Walvalkar A, et al. Leucine125 Valine (Leu 125Val) gene polymorphism of platelet endothelial cell adhesion molecule-1 (PECAM-1) and myocardial infarction in Indian Population. Ind J Clin Biochem. 2010; 25(3): 273-279.

29. Fang L, Wei H, Chowdhury SH, Gong N, Song J, Heng CK, et al. Association of Leu125Val polymorphism of platelet endothelial cell adhesion molecule-1 (PECAM-1) gene \& soluble level of PECAM-1 with coronary artery disease in Asian Indians. Indian J Med Res. 2005; 121(2): 92-99.

30. Listi F, Caruso C, Di Carlo D, Falcone C, Boiocchi C, Cuccia M, et al. Association between platelet endothelial cellular adhesion molecule-1 polymorphisms and atherosclerosis: results of a study on patients from northern Italy. Rejuvenation Res. 2010; 13(2-3): 237-241.

31. Xia T, Liu X, Jiang CD, Jin X, Kong XQ, Li G. Association of Leu125Val polymorphisms in the PECAM-1 gene with the risk of coronary heart disease: a meta-analysis. Int J Clin Exp Med. 2015; 8(2): 2219-2225. 
32. Moreno PR, Fuster V. New aspects in the pathogenesis of diabetic atherothrombosis. J Am Coll Cardiol. 2004; 44(12): 2293-2300.

33. Grundy SM, Benjamin IJ, Burke GL, Chait A, Eckel RH, Howard BV, et al. Diabetes and cardiovascular disease: a statement for healthcare professionals from the American Heart Association. Circulation. 1999; 100(10): 1134-1146. 